\title{
Os pronomes clíticos em contextos infinitivos no português antigo
}

\section{Old Portuguese clitic pronouns in infinitive contexts}

\author{
Sandra Pereira \\ Faculdade de Letras, Centro de Linguística da Universidade de Lisboa (Portugal) \\ sandra.pereira@campus.ul.pt
}

Recibido o 09/04/2018

Aceptado o 21/10/2018

\section{Resumo}

O fenómeno da subida do clítico é amplamente referido na literatura como uma propriedade dos complexos verbais seja na construção de reestruturaçáo (Rizzi 1982) seja na construção Fazer-Inf (Kayne 1975). Através de um estudo quantitativo a partir de três textos literários, este trabalho tem como objetivo descrever a colocação dos pronomes clíticos em português antigo. São inspecionados dois contextos específicos: i) complexos verbais de reestruturação (para identificar quais os verbos que a permitiam em português antigo) e ii) oraçóes de infinitivo simples e flexionado preposicionadas (para verificar se a preposição é determinante para a posiçáo do clítico, partindo das assunções feitas por Martins 1994 de que, ao longo do século XIII e na primeira metade do XIV, havia instabilidade no padrão de colocação dos pronomes clíticos). No final, verificar-se-á que o padrão de colocação dos pronomes clíticos nas oraçóes de infinitivo simples introduzidas por preposiçáo contribui para a clarificação da fidelidade das cópias tardias de dois textos originais do século XIII.

\section{Palabra chave}

Subida do clítico; construçâo de reestruturação; oraçôes infinitivas preposicionadas; português antigo

\section{Sumario}

1. Introdução. 2. Metodologia. 2.1. O corpus. 2.2. Dados excluídos. 2.2.1. Grafia do editor. 2.2.2. Duplicação do clítico. 2.2.3. Casos de coordenação. 2.2.4. Verbos causativos e percetivos. 3. Os dados considerados. 3.1. Complexos verbais. 3.2. Oraçóes infinitivas preposicionadas. 3.2.1. Infinitivo simples. 3.2.1.1. Introduzidas por $a$. 3.2.1.2. Introduzidas por de. 3.2.1.3. Introduzidas por em. 3.2.1.4. Introduzidas por para. 3.2.1.5. Introduzidas por por. 3.2.1.6. Introduzidas por sem. 3.2.2. Infinitivo flexionado. 4. Considerações finais.

\section{Abstract}

The clitic raising phenomenon is broadly referred to in the literature as a property of verbal complexes, found not only in the restructuring construction (Rizzi 1982) but also in the Fazer-Inf construction (Kayne 1975).Through a quantitative study from three literary texts, the current study aims to describe the placement of clitic pronouns in Old Portuguese. Two specific contexts are analysed: i) verbal complexes of restructuring (in order to identify which verbs allowed it in Old Portuguese) and ii) prepositional infinitival clauses with simple and inflected infinitive (in order to verify whether the preposition is relevant for the position of the clitic, taking into account the assumptions made by Martins 1994 that, throughout the thirteenth century and the first half of the fourteenth century, there was instability in the clitic pronouns placement pattern). In the conclusion, it will be seen that the placement pattern of clitic pronouns in the simple infinitive clauses introduced by a preposition contributes to the clarification of fidelity of the late copies of two 13th century original texts.

\section{Keywords}

Clitic climbing; restructuring construction; prepositional infinitival clauses; Old Portuguese

\section{Contents}

1. Introduction. 2. Methodology. 2.1. Corpus. 2.2. Excluded data. 2.2.1. Editor's spelling. 2.2.2. Clitic duplication. 2.2.3. Coordination cases. 2.2.4. Causative and perception verbs. 3. The considered data. 3.1. Verbal complexes. 3.2. Prepositional infinitival clauses. 3.2.1. Impersonal infinitive. 3.2.1.1. Introduced by $a$. 3.2.1.2. Introduced by de. 3.2.1.3. Introduced by $\mathrm{em}$. 3.2.1.4. Introduced by para. 3.2.1.5. Introduced by por. 3.2.1.6. Introduced by sem. 3.2.2. Personal infinitive. 4. Final considerations. 


\section{Introdução}

U M dos objetivos deste trabalho é descrever, do ponto de vista linguístico, o padrão de colocação dos pronomes clíticos em dois contextos: i) em complexos verbais que permitem a construção de reestruturação (cf. Gonçalves 1999) e ii) em oraçôes de infinitivo introduzidas por preposição no português antigo (daqui em diante, PA) ${ }^{1}$.

A elevação do pronome clítico para o domínio finito mostra que o complemento infinitivo selecionado por determinados verbos é transparente para certas operaçóes sintáticas. Vejam-se os exemplos em (1):

(1a) A mãe foi- $a$ buscar à escola. " subida do clítico

(1b) A mãe foi buscá-la à escola. " não subida do clítico

Em (1a), o pronome acusativo, que é complemento de buscar, juntou-se ao verbo finito enquanto em (1b) se manteve junto ao verbo do qual depende. A este movimento do pronome para junto do verbo do domínio superior chama-se subida do clítico (cf. Martins 1994; Mateus et al. 2003, entre muitos outros). Os predicados complexos envolvidos neste tipo de fenómeno podem ser de dois tipos: reestruturação (cf. Rizzi 1982) ou construção de União de Oraçôes (ou Fazer-Inf, cf. Kayne 1975). Estas construçóes têm características diferentes e, no âmbito deste trabalho, será apenas considerada a construção de reestruturação ${ }^{2}$.

De acordo com Martins (1994, 2016b: 419), a subida do clítico era um fenómeno generalizado em português até ao século Xvı, altura em que a ocorrência do clítico junto ao verbo infinitivo se vai tornando mais frequente. Assim, espera-se que, sendo anteriores ao século XVI, os dados do corpus considerado para este estudo reforcem essa generalização ${ }^{3}$.

A preposição que introduz a oração infinitiva parece ter alguma influência na posição do pronome átono no que aos complexos verbais diz respeito mas também nos casos em que náo há evidência para considerar que houve a formaçáo de um

1. Cf. Martins (2016a: 12) para periodização da história da língua portuguesa. Segundo esta autora, o período do Português Antigo vai até ao final do séc. XIV.

2. Entre outras propriedades (cf. Gonçalves 1999), a construçáo de União de Oraçóes distingue-se da construção de reestruturação por:

Sofrer uma alteração na ordem dos constituintes do domínio infinitivo (relacionada com a redefinição de funções sintáticas);

Não poder ocorrer na forma passiva;

Não apresentar restriçóes quanto à natureza do clítico.

Cf. também Gonçalves et al. (2016: 535-536).

3. O português segue a tendência das outras línguas românicas que, ao longo da sua história, vão diminuindo os valores de subida do clítico, tornando-se este fenómeno facultativo ou mesmo inexistente (como é o caso atualmente do francês, cf. Wanner 1987: 299). 
predicado complexo, ou seja, em oraçôes infinitivas introduzidas por preposição (cf. (3a) e (3b)).

(2a) O Pedro começou- $a$ a ler na semana passada.

(2b) O Pedro começou a lê-la na semana passada.

(3a) Trabalhei por me ir embora cedo para não apanhar trânsito. prep-CL-Inf (próclise)

(3b) Trabalhei por ir-me embora cedo para não apanhar trânsito. " prep-Inf-CL (ênclise)

Estas questóes foram já abordadas por Martins (1994) num estudo que analisava textos notariais do PA e por Fiéis e Madeira (2012), entre outros. Foram igualmente estudadas para o português europeu contemporâneo por autores como Gonçalves (1999), Magro (2005) e Barbosa et al. (2017), citando apenas alguns.

Os textos selecionados para este estudo foram $O$ Livro de José de Arimateia (daqui em diante, Arimateia), a Demanda do Santo Graal (Demanda, daqui em diante) e $A$ Crónica Geral de Espanha de 1344 (Crónica) ${ }^{4}$. Sabendo que este data do século XIv, os dois primeiros, sendo cópias tardias de um original do século XII, apresentam outros desafios.

O Arimateia e a Demanda são dois textos do ciclo arturiano traduzidos para português no século XIII (Post-Vulgata), que chegaram até nós através de cópias tardias com cronologias distintas: a Demanda através de uma cópia quatrocentista e o Arimateia através de uma cópia mais tardia, quinhentista. Nas palavras de Martins (2013): "podemos admitir que tanto no caso do José de Arimateia como no da Demanda temos hoje acesso a manuscritos que embora tardios relativamente à data da tradução, foram produzidos a partir de exemplares que representariam bem o texto português primitivo" ${ }^{5}$. No entanto, "o estrato duocentista é menos nítido no José de Arimateia" já que parece ter havido uma intenção clara de eliminar formas consideradas antigas (cf. Martins 2013 para a comparação entre as duas cópias - do Arimateia e da Demanda - feitas em séculos diferentes e o estudo de distintos estratos linguísticos). Será interessante perceber se, à luz das questôes inspecionadas ao longo deste trabalho, essa intenção dos copistas do Arimateia é também evidenciada ao nível da sintaxe, no que diz respeito especificamente à subida do clítico e à posição do pronome em oraçóes infinitivas preposicionadas.

4. $\mathrm{Na}$ identificação dos exemplos ao longo do texto será usada a seguinte codificação: JAR para o Arimateia, DSG para a Demanda e CGE para a Crónica. Essa codificação contém a identificação de cada frase anotada e é gerada automaticamente no processo de anotação, mantendo-se nas extraçóes efetuadas que constituem os exemplos ao longo do texto.

5. Daí considerar-se que se trata de textos do português antigo (cf. nota 1). 
É também, portanto, objetivo deste trabalho, contribuir, do ponto de vista filológico, para a clarificação da fidelidade das cópias (relativamente ao original) do Arimateia e da Demanda (cf. Martins 2013). Uma vez que a subida do clítico foi generalizada e constante até ao séc. XVI, não é expectável que este fenómeno aponte pistas para o grau de fidelização das cópias, cujas datas (do original e da cópia) se encontram abrangidas por este período. Contrariamente, e de acordo com as assunções de Martins (1994; 2016b), em oraçôes infinitivas preposicionadas, com determinadas preposiçóes verifica-se alguma mudança a partir de meados do século XIV pelo que se espera que a posição do pronome clítico nestas oraçóes possa sugerir uma aproximação ou um afastamento relativamente ao original duocentista, anterior à mudança assinalada pela autora.

O artigo está organizado da seguinte maneira: para além desta secção introdutória, na secção seguinte, são descritas algumas questôes metodológicas que nortearam o trabalho (como o corpus selecionado e a pertinência de classificação e exclusão de alguns dados); seguidamente, na secção 3, serão apresentados os dados do corpus (sobre a subida do pronome nos complexos verbais e sobre a posição do pronome em orações infinitivas introduzidas por preposição); finalmente, na secção 4, serão feitas algumas consideraçôes finais sobre os dados apresentados.

\section{Metodologia}

Algumas informaçóes sobre o corpus usado no âmbito deste trabalho e sobre questóes metodológicas são abordadas seguidamente.

\subsection{O corpus}

Como já foi dito, o corpus é composto por três textos literários do PA: o Arimateia, a Demanda e a Crónica.

A edição do Arimateia usada neste trabalho foi a de Castro (1984) e, no caso da Demanda, usou-se a transcrição de Neto (2012-1015). Os dois textos foram considerados na íntegra ${ }^{6}$, a partir da anotaçáo levada a cabo no projeto WOChWEL .

A Crónica é um texto do século xiv e a edição usada neste trabalho foi a edição digital preparada por Miranda (2013), a partir de Cintra (1951-1961). Foram con-

6. O número de palavras do Arimateia ronda as 142 mil e a Demanda tem cerca de 216 mil palavras. 7. O projeto WOChWEL (Word Order and Word Order Change in Western European Languages) decorreu no Centro de Linguística da Universidade de Lisboa de 2012 a 2015. Mais informaçôes em: http://alfclul.clul.ul.pt/wochwellindex.html. 
siderados apenas os capítulos 305 a 800, por terem sido estes os capítulos anotados e disponibilizados no âmbito do projeto Arquidia ${ }^{8}$.

O corpus considerado neste estudo, composto pelos três textos, Arimateia (integral), Demanda (integral) e Crónica (parcial), ultrapassa as 605 mil palavras. A extração dos dados que são analisados na secção seguinte foi feita a partir de uma versão dos textos anotada sintaticamente e com recurso a pesquisas que agilizaram todo o processo de seleção dos dados? .

No total e após seleção manual, foram consideradas 3532 ocorrências, extraídas a partir do Arimateia ${ }^{10}$, da Demanda ${ }^{11}$ e da Crónica ${ }^{12}$ :

i. 2633 casos que envolvem verbos que permitem a formação da construção de reestruturação

ii. 758 que envolvem oraçóes de infinitivo simples introduzidas por preposição e

iii. 141 ocorrências de oraçôes de infinitivo flexionado introduzido por preposição.

Quer no caso dos verbos de reestruturação quer no caso das infinitivas preposicionadas não foram tidos em conta os diferentes contextos de colocação de clíticos ${ }^{13}$. Assim, interessa verificar se há ou não subida do clítico e se a preposição tem um papel relevante na colocação do pronome.

Importa aqui considerar alguns aspetos importantes na classificação dos dados. Em PA, os casos de subida do clítico eram predominantes (cf. (4)) havendo pontualmente contextos em que o clítico ficava junto ao verbo infinitivo (5):

(4) - Donzela, disse ele, ligeyramente o podedes fazer. (JAR111,.8)

8. O Arquídia (Arquivo dialetal e diacrónico) é um projeto em curso no Centro de Linguística da Universidade de Lisboa. A anotação de um texto medieval é um dos objetivos do projeto, tendo, para isso, sido selecionada uma parte da Crónica (essa parte selecionada tem quase 250 mil palavras).

9. O sistema de anotação sintática adotado codifica, entre outros fenómenos, fronteiras de constituintes, movimentos, categorias vazias e indexaçóes, o que facilita a pesquisa de construçôes sintáticas. Para este trabalho, de modo simplificado, no caso da subida de clítico, pesquisou-se um domínio infinitivo com uma posição vazia coindexada com um pronome clítico no domínio finito; para o caso da não subida, procurou-se pelos contextos em que, podendo ter ocorrido a subida, o pronome se manteve no domínio infinitivo. No que às oraçôes infinitivas preposicionadas diz respeito, a pesquisa incidiu sobre sintagmas preposicionais que dominassem oraçóes infinitivas com um pronome átono antes ou depois do verbo infinitivo.

10. Disponível em: http://alfclul.clul.ul.pt/wochwel/documents/Jos\%C3\%A9\%20Arimateia.psd .

11. Disponível em: http://alfclul.clul.ul.pt/wochwel/documents/Demanda_Santo_Graal.psd.

12. Disponível em: http://alfclul.clul.ul.pt/wochwel/documents/CGE305_800.psd .

13. Será um trabalho a desenvolver no futuro e será interessante analisar se, em termos gerais, os resultados serão diferentes. 
(5) Disto foy o duque muy espantado e preguntara a Josefes que maravilha seria, se nom cuydara de o anojar. (JAR96,.21)

Para além destes casos de subida e não subida do pronome que não levantam problemas uma vez que é fácil identificar o domínio onde o clítico ocorre, exemplos como os que se seguem foram considerados, na linha de Martins (1994), como instâncias de subida do clítico. Assim, em (6), porque há a interpolação do verbo infinitivo entre o clítico e o verbo finito, fenómeno comum em PA, considera-se que o clítico subiu para o domínio finito; em (7) e (8), há a subida do verbo infinitivo e do clítico, assumindo-se que este se encontra igualmente no domínio superior.

(6) E esto digo eu por mỹ e por aqueles que o fazer quiserem comigo. (CGE750a,.36)

(7) - Sobrynhos, dizer-vos quero o que tenho por bem de fazer. (CGE372,.5)

(8) - Matar-me podes, se te apraz, que teu é ora o poder. (JAR111,.40)

$\mathrm{Na}$ verificação manual dos resultados, verificou-se ainda que alguns contextos de ocorrência de clíticos não podiam ser considerados por motivos vários. Apresentam-se, de seguida, esses contextos.

\subsection{Dados excluídos}

\subsubsection{Grafia do editor}

Foram excluídos deste estudo os casos em que o editor optou por grafar o pronome separadamente, como em (9) ${ }^{14}$, por se tratar de casos que envolvem opçóes de edição e náo ser claro se o clítico pertence ao domínio superior ou ao domínio infinitivo, já que se encontra entre os dois verbos:

(9) E, se o eu fiz, quero vo-lo correger a vossa vontade e segundo eu puder. (JAR89,.63)

Igualmente, os casos em que o editor (sobretudo na Crónica) optou por não grafar a mesóclise, deixando o verbo haver isolado, como em (10), também não foram considerados:

14. Os casos em que há evidência para considerar que o clítico se encontra naquele domínio específico por haver algum elemento a quebrar a adjacência entre o pronome e um dos verbos foram considerados. No exemplo seguinte, na linha de Martins (1994: 153), o clítico liga-se ao auxiliar uma vez que a negação que ocorre entre o clítico e o verbo infinitivo marca a fronteira de um domínio diferente:

E, quando Vespesiano isto ouvio, jurou que os queimaria todos se lhe não mostrassem donde era e eles disserão: - Queimar-nos podeis vós, mas dar nom vo-lo podemos, que nom sabemos dele nada. (JAR23,.17) 
(10) Pero, pera vos ajudar, ẽvyar-lho ey dizer. (CGE631,.10)

\subsubsection{Duplicação do clítico}

Da mesma forma, os casos em que havia duplicação do pronome ${ }^{15}$, como se exemplifica em (11) e (12), também não foram considerados. Assim, o pronome está repetido nas duas posiçóes possíveis: em (11), encontra-se junto ao verbo finito e também antes do verbo infinitivo; em (12), o pronome $o$ também ocorre imediatamente antes do verbo e imediatamente a seguir.

(11) E começou-hos de os affaagar, dizendo que nô ouvessem querella delle por a orta que dera ao Cide, (CGE604,.10)

(12) E, por $o$ assessega-lo, disse que o queria casar. (CGE773,.6)

\subsubsection{Casos de coordenação}

No corpus, foram encontrados vários casos de coordenação (com elipse do verbo finito). Nem todos foram contabilizados para este estudo como a seguir se explicita ${ }^{16}$.

(13) ora é direito que dês à Santa Igreja o que lhe prometeste, que a devias acrecentar e enxaltar por todo o mundo, (JAR38,.11)

(14) E o conde dom Ârrique desafiou-ho pera lydar con elle, ca o cuydou de vençer e the tomar a terra. (CGE735,.9)

(15) quando vy்u Galuam que era morto, começou a fazer seu doo grande aa marauilha e $a$ doestar-sse e a maldizer-sse muito. (DSG271,.2)

Como se pode verificar em (13), há apenas um verbo finito (dever) e dois verbos infinitivos (acrecentar e enxaltar). Havendo a elipse do verbo finito e como o pronome não é repetido junto ao segundo verbo, o que geralmente acontece em PA, optou-se por excluir estes exemplos.

15. Para o estudo deste fenómeno nos dialetos do português contemporâneo, veja-se Magro (2007). 16. Por sugestão de um revisor deste trabalho, os dados do tipo dos apresentados em (13)-(15) não foram contabilizados, ainda que, numa primeira versão deste trabalho o tenham sido. É por essa razão que é possível afirmar que a construção com coordenaçáo de verbos infinitivos com o clítico a ocorrer também junto do segundo é mais frequente do que a construção ilustrada pelo exemplo (13) na qual o pronome, tal como o verbo finito, só ocorre uma vez. Há obviamente fatores (pronomes de natureza diferente, verbos com grelhas argumentais distintas) que contribuem para a frequência da primeira e que determinam que o clítico fique junto ao segundo verbo obrigatoriamente. 
Em (14), os clíticos dos dois verbos infinitivos são diferentes: o do primeiro sobe e o do segundo tem de ficar necessariamente junto ao verbo infinitivo (porque há a elipse do verbo superior); no exemplo (15), há a coordenação de três verbos infinitivos, sendo que o primeiro não tem nenhum pronome clítico como argumento e os clíticos dos segundo e terceiro verbos ocorrem junto aos mesmos (note-se que a preposição $a$ também ocorre junto de cada verbo coordenado). Em (14) e (15), devido à natureza do pronome e à grelha argumental do verbo infinitivo, o clítico ocorre sempre obrigatoriamente junto a este, já que, com a elipse do verbo superior a hipótese de subida não se póe. Por esta razão, estes casos foram descartados.

Contrariamente, quando a omissão do clítico no segundo verbo infinitivo não acontece, em casos em que os clíticos dos verbos infinitivos são iguais, assume-se que a subida não se dá (já que o pronome ocorre junto ao verbo infinitivo do qual depende), como em (16) e (17), e os exemplos foram considerados:

(16) entendeu que se nô poderia teer com el rey dom Sãcho nem defender-sse delle. (CGE360,.5)

(17) E elles, quando esto vyró, de cada parte me começaró de ameaçar e fazer-me muyto mal ẽ mynha terra quãto podyá. (CGE339,.12)

No exemplo (16), o clítico se sobe para o domínio superior ${ }^{17}$ e não ocorre junto ao primeiro verbo infinitivo mas ocorre junto ao segundo (defender-sse), o que acontece também em (17) (havendo, neste caso, a particularidade de não ocorrer também a preposição de junto ao segundo verbo infinitivo).

Assim, no âmbito deste estudo, apenas foram contabilizados exemplos do tipo de (16) e (17): casos em que os clíticos dos verbos infinitivos são da mesma natureza e não se encontram omissos (em contraste com (13).

\subsubsection{Verbos causativos e percetivos}

Os verbos causativos e os verbos percetivos também podem estar envolvidos na formação de complexos verbais, aos quais se chamam União de Oraçôes (ou Fazer-Inf., cf. Kayne 1975 e, para o português, Gonçalves 1999). Mas, uma vez que levantam questôes diferentes das dos outros verbos que também possibilitam a formação de outro tipo de predicados complexos (como a construção de reestruturação), não foram considerados para este estudo. Sendo igualmente possível a subida do pronome

17. Em PA, o clítico podia estar em posição pré-verbal sem ocorrer em adjacência ao verbo finito, como acontece em (16): entre o pronome se e o verbo finito (poderia) ocorre a partícula de negação (nô). Sobre este fenómeno, conhecido na literatura como Interpolação, cf. Martins (1994) para o PA, e para o português europeu contemporâneo, cf. Magro (2007). 
com estes verbos, as construções têm características diferentes das que serão analisadas no âmbito deste trabalho ${ }^{18}$. Assim, frases como as que se seguem foram retiradas:

(18) E o Cide deu entom a espada Collada a Martĩ Antoniiz e mãdou-hos tornar pera el rei. (CGE663,.9)

(19) E, quando ho eu vi, conhiçi-o e vi-o ffugir. (DSG227,.15)

\section{Os dados considerados}

\subsection{Complexos verbais}

É sabido que o fenómeno de subida do clítico é um dos testes usados para a identificação dos predicados complexos (cf. para o português, Gonçalves 1999; Magro 2005; Barbosa et al. 2017). Quando a sequência de dois ou mais verbos tem coesão sintático-semântica há a formação de um predicado complexo. Seguindo Rizzi (1982), estes predicados complexos apresentam propriedades como:

- Subida do clítico

- Movimento longo de objeto

- Escolha do auxiliar nos tempos compostos

De acordo com o tipo de verbos, estes predicados complexos podem ser de dois tipos:

i) Com verbos de controlo e elevaçãa ${ }^{19}$ : reestruturação

ii) Com verbos causativos e percetivos: Uniấo de Oraçóes

Dada a natureza do corpus, neste trabalho pretende-se apenas explorar os verbos que em PA permitiam a subida do pronome possibilitando assim a formação de predicados de reestruturação (já que os verbos causativos e percetivos foram excluídos). Magro (2005) assume que em alguns dialetos do português há mais verbos a permitirem a subida do clítico do que no português padrão. Será interessante verificar se neste corpus do PA há igualmente mais verbos do que atualmente a possibilitarem esse fenómeno (quer na variedade padrão quer dialetalmente).

\section{Cf. nota 2 .}

19. Nem todos os verbos de controlo e de elevaçáo permitem a subida do pronome para junto de si em PA e em português contemporâneo. De entre os verbos de controlo destaca-se o verbo querer; entre os verbos de elevaçáo que permitem a construçáo estâo os verbos semiauxiliares modais (poder, dever (al de)), aspetuais (começar alde), temporais (vir). 
Em termos gerais, os valores de subida do clítico são bastante elevados, como é expectável. Também em termos de texto isoladamente, a não subida é residual: no Arimateia, há apenas 49 casos em 690; na Demanda, 21 em 1024; na Demanda, são 60 casos em 921. A seguir apresentam-se e comentam-se estes dados detalhadamente.

$\mathrm{Na}$ Tabela 1 estấo os verbos que apresentam sempre subida de clítico.

\begin{tabular}{|c|c|c|c|}
\hline verbo com subida & CL-V & $\mathrm{V}-\mathrm{CL}$ & total \\
\hline acabar de & 2 & & 2 \\
\hline aduzir a & 1 & & 1 \\
\hline ajudar a & 3 & & 3 \\
\hline cobiçar a & 1 & & 1 \\
\hline começar & & 4 & 4 \\
\hline convir & 1 & & 1 \\
\hline crer & & 1 & 1 \\
\hline cuidar & 9 & 2 & 11 \\
\hline cuidar a & 10 & 2 & 12 \\
\hline cumprir & 1 & & 1 \\
\hline deixar a & 7 & & 7 \\
\hline desejar a & 10 & & 10 \\
\hline entender de & 1 & & 1 \\
\hline haver & 3 & 1 & 4 \\
\hline haver a & 13 & 3 & 16 \\
\hline haver de & 93 & 14 & 107 \\
\hline ir a & 2 & 1 & 3 \\
\hline ousar & 39 & & 39 \\
\hline prometer & 1 & 1 & 2 \\
\hline sair & 1 & & 1 \\
\hline soer & 1 & & 1 \\
\hline soer a & 2 & & 2 \\
\hline soer de & 5 & & 5 \\
\hline temer de & 1 & & 1 \\
\hline tolher de & & 1 & 1 \\
\hline TOTAL & 207 & 30 & 237 \\
\hline$\%$ & 87,3 & 12,7 & 100 \\
\hline
\end{tabular}

Tabela 1. Verbos que apresentam sempre subida do clítico: próclise (CL-V) ou ênclise (V-CL) ao verbo finito 
Se observarmos a tabela com atenção, verificamos que, independentemente da preposição que segue o verbo, são 20 os verbos que apresentam sempre subida do clítico e permitem, portanto, a formação de um complexo verbal já que em todas as ocorrências destes verbos no corpus o clítico está junto ao verbo finito seja em posição pré-verbal (próclise: 207 casos) ou pós-verbal (ênclise: 30 casos). Alguns destes verbos, como acabar de, ir a, soer (alde), estão já identificados em estudos anteriores (cf. Martins 1994; Fiéis \& Madeira 2012) como verbos que permitem a subida do clítico. Há, contudo, na tabela outros verbos que, por exemplo, em português europeu contemporâneo (padrão e dialetal), bloqueiam a subida do clítico, como o verbo sair, mas que a permitem em PA (cf. (20)). Nos dados de Fiéis e Madeira (2012), as autoras elencam o verbo prometer como um verbo que não permite a elevaçáo do clítico contrariamente ao verbo esperar ${ }^{20}$. Os dados deste estudo parecem revelar outra tendência. Salienta-se também a subida com o verbo convir que se ilustra em (22):

(20) E, tanto que Nasçiáo ouvio que sua molher o saíra buscar, mandou homes por todas partes que a fossem buscar. (JAR87,.67)

(21) De hoje mais, quero eu que tu recebas a honra que te prometi dar e saberás que é o sacramento da minha carne e do meu sangue, (JAR41,.30)

(22) Por a fonte que viste na montanha, onde se convinháo lavar todos os que a festa iam, deveis de entender a santa augua do bautismo, (JAR77,.85)

Outro aspeto importante sobre estes verbos é que, enquanto alguns permitem a subida independentemente da preposição (soer, soer $a$, soer de ou cuidar, cuidar $a$, ou ainda haver, haver a, haver de), há outros, como começar ou ousar, que se comportam de maneira diferente, de acordo com o elemento que introduz o verbo infinitivo ${ }^{21}$. Assim, com as preposiçóes a (cf. (23) e (26)) e de (cf. (24) e (27)) o clítico nem sempre sobe mas quando a preposição não ocorre há sempre subida, seja com o verbo começar (cf. (25)), ousar (cf. (28)) ou sair (cf. (20) acima):

20. No corpus aqui considerado há apenas um exemplo com esperar e não apresenta subida do pronome:

E os del-rei Tolomer, ainda que, sem seu senhor, estavam considerando estarem em terra estranha e donde nom esperavam sair-se, defendiam mui bravamente, estando todos cercados dos del-rei Evalac. (JAR50,.100)

21. É a pensar nessas diferenças de comportamento que, neste trabalho, os verbos com diferentes preposiçóes são sempre apresentados separadamente nas tabelas. Dependendo do verbo que as rege, as preposiçóes podem aproximar-se mais de verdadeiras preposiçóes ou de complementadores. Sobre o estatuto das preposiçóes que introduzem oraçóes infinitivas em português, ver Magro (2005) e Gonçalves et al. (2007). 
(23) E o caualeyro que lhe querya grá mal, que era muyto boóo caualeyro d armas e sãão e ligeyro, começou a o trager aa espada talhador hũa ora $\mathrm{d}$ aca e outra $\mathrm{d}$ ala, (DSG274,.5)

(24) E elle, quando o vyo, começou de o afaagar; e o moço chorava muy fortemente. (CGE733,.23)

(25) E tanto que esto disse, começou-se hir assi de nocte como era e Galuam ficou na hermjda. (DSG140,.15)

(26) Ca ja eu outra uez uy esta spada e nó ousey a proua-lla. (DSG20,.11)

(27) Mas ele soo é todo seu bem e os sostem e nunca se vio tal cousa, que nhum dos vossos nom ousa de o esperar. (JAR50,.12)

(28) Mas, pero que se em esto acordaró, nó ho ousarom cometer por medo del rei. (CGE664,.10)

Com o verbo ir, o cenário é exatamente o oposto: assim, com ir a, há sempre subida e quando o verbo ocorre sem preposição pode ficar junto do verbo infinitivo, como ilustram os exemplos (29) e (30):

(29) E el rei se foy a sentar na sua alta seeda. (DSG15,.4)

(30) E Mauter, des que vio o mandado del-rei, houve grão prazer e foi feri-los tam bravamente que os fez sair do campo quanto um tiro de besta. (JAR50,.14)

O caso do verbo desejar é ligeiramente diferente já que, de acordo com os dados extraídos destes textos, apresenta obrigatoriamente subida se a preposição for $a$ mas não com $d e$ :

(31) Mas por Deus, se uos sabedes u morou ata aqui, dizede-mo ca muẏto $o$ deseio a ssaber. (DSG707,.18)

(32) Quando el-rey foy a ermida, o duque o seguio todo armado, com dous cavaleiros, como homem que dezejava de se vingar. (JAR119,.24)

Para além destes verbos listados na Tabela 1 com os quais a subida é perentória, foram encontrados outros verbos que não apresentam subida obrigatória, havendo a possibilidade de o clítico permanecer junto ao verbo infinitivo. Esses verbos estão elencados na Tabela 2, que indica os valores da subida e não subida ${ }^{22}$.

22. Os "outros" apresentados na Tabela dizem respeito aos casos exemplificados anteriormente (cf. exemplos (6)-(8)) em que não há necessariamente a ordem CL-V ou V-CL. 


\begin{tabular}{|c|c|c|c|c|c|c|c|c|c|c|}
\hline \multirow[t]{2}{*}{ VERBO } & \multicolumn{5}{|c|}{$\operatorname{sim}$} & \multicolumn{4}{|c|}{ não } & \multirow[t]{2}{*}{ TOTAL } \\
\hline & CL-V & $\mathrm{V}-\mathrm{CL}$ & outros & total & $\%$ & CL-Inf & Inf-CL & total & $\%$ & \\
\hline começar a & 16 & 36 & & 52 & 94,5 & 1 & 2 & 3 & 5,5 & 55 \\
\hline começar de & 6 & 20 & & 26 & 35,6 & 45 & 2 & 47 & 64,4 & 73 \\
\hline cuidar de & 6 & 7 & & 13 & 48,1 & 13 & & 13 & 51,9 & 26 \\
\hline deixar de & 11 & & & 11 & 91,7 & 1 & & 1 & 8,3 & 12 \\
\hline desejar & 3 & & & 3 & 75 & & 1 & 1 & 25 & 4 \\
\hline dever & 66 & 3 & 1 & 70 & 95,9 & & 3 & 3 & 4,1 & 73 \\
\hline dever a & 27 & 9 & & 36 & 97,3 & & 1 & 1 & 2,7 & 37 \\
\hline dever de & 34 & 2 & & 36 & 97,3 & 1 & & 1 & 2,7 & 37 \\
\hline ir & 85 & 96 & & 181 & 97,8 & & 4 & 4 & 2,2 & 185 \\
\hline ousar a & 5 & & & 5 & 83,3 & & 1 & 1 & 16,7 & 6 \\
\hline ousar de & 13 & & & 13 & 81,3 & 3 & & 3 & 18,8 & 16 \\
\hline pensar de & 1 & & & 1 & 16,7 & & 5 & 5 & 83,3 & 6 \\
\hline poder & 897 & 7 & 19 & 923 & 99,2 & & 7 & 7 & 0,8 & 930 \\
\hline querer & 622 & 89 & 12 & 723 & 98,5 & & 11 & 11 & 1,5 & 734 \\
\hline saber & 46 & 1 & & 47 & 97,9 & & 1 & 1 & 2,1 & 48 \\
\hline sair a & 3 & 25 & & 28 & 62,2 & 9 & 8 & 17 & 37,8 & 45 \\
\hline ter de & 2 & & & 2 & 66,7 & 1 & & 1 & 33,3 & 3 \\
\hline tornar a & 7 & 2 & & 9 & 90 & & 1 & 1 & 10 & 10 \\
\hline trabalhar & & 1 & & 1 & 50 & 1 & & 1 & 50 & 2 \\
\hline vir & 76 & 10 & & 86 & 96,6 & & 3 & 3 & 3,4 & 89 \\
\hline \multirow[t]{2}{*}{ vir a } & 1 & & & 1 & 20 & 4 & & 4 & 80 & 5 \\
\hline & 1927 & 308 & 32 & 2267 & 94,6 & 79 & 50 & 129 & 5,4 & 2396 \\
\hline
\end{tabular}

Tabela 2. Verbos que apresentam subida e não subida do clítico

Ainda que com alguns verbos a subida seja menos frequente (como começar de, cuidar(-se) de, pensar de e vir a), com a grande maioria destes verbos a subida do clítico é predominante (quase 95\% das 2397 ocorrências). Seguem-se alguns exemplos que exemplificam a oscilação na colocação do clítico com o verbo pensar ((33) e (34)), começar de ((35) e (36)), sair a ((37) e (38)), ter de ((39) e (40)), dever ((41) e (42)), poder ((43) e (44)) e querer ((45) e (46)):

(33) Soo nô no penssedes de vençer nem curees de uos tomar cô elle, ca bem ssabedes que lhe nô poderedes durar nenhũa maneyra uos nẽ caualleyro nenhũũ que ora no mũdo aja. (DSG222,.14) 
(34) E, veendo ella como elle era en hidade pera aver molher, pésou de o casar con hũa filha de dom Filippe, rey d' Alemanha, que avya nome dona Beatriz. (CGE782,.7)

(35) E começaram-nos de ferir e derribar tam mortalmente que a pouco de hora ficaram de mortos e feridos mais de duzentos na hoste. (JAR98,.8)

(36) E começou de muito lhe pesar em seu coraçam da vontade que depois tivera $\mathrm{e}$ começou a pedir a Deos merce. (JAR64,.31)

(37) E desi tornou-sse pera Vallecça cô muy grande riqueza e el rei sayu-ho a receber com grande honrra. (CGE582,.13)

(38) E, quando o conde soube que viinhã, sayu a recebe-llos. (CGE378,.77)

(39) "Rogo-vos que honredes bẽe o Salvador do mundo e esqueçades as imagens que nom tem poder de ajudar, antes o tem de empencer". (JAR52,.55)

(40) E el rei fora entã ouujr missa à see com gram conpanha de caualeyro que maraujlha terriades de os neer. (DSG08,.5)

(41) E bem no devês ver por estas images que vós chamades Deos, que ele queimou. (JAR105,.120)

(42) E como quer que ell erasse contra ty் mui mas ca nô deueria perdoar-lhe, sse ty் prouguer. (DSG270,.9)

(43) - Matar-me podes, se te apraz, que teu é ora o poder. (JAR111,.40)

(44) Aquele que perdeo a vista e a fala poderá jamais cobrá-la? (JAR45,.18)

(45) E esto digo eu por mỹ e por aqueles que o fazer quiserem comigo. (CGE750a,.36)

(46) ca ante eu quero cô meus filhos yr-me pera terra de mouros que seermos vẽçudos ẽ cápo e ficarmos por aleyvosos. (CGE505,.15)

(47) E vós trabalhade-vos defender com dereito. (CGE655,.21)

(48) E os iffātes, quando os assy virô vĩir, temerô-sse delles e trabalharom escusar-sse delles com pallavras e disseron-lhe: (CGE643,.15)

(49) E, se vejo o filho da arrenegada, cuydo-lhe de dar hũu tal golpe que me nó ficara ẽ sella. (CGE379,.68)

(50) E elles cuidavam de the tolher a terra, por que tragiam o menino consigo. (CGE735,.7)

Note-se que, como já foi referido anteriormente, os exemplos apresentados em (43) e (45) representam casos de subida do clítico: em (43), há a subida do verbo infinitivo e do clítico e, em (45), o verbo infinitivo está interpolado entre o clítico e o verbo finito, fenómeno comum em PA (cf. Martins 1994).

Observa-se também que com o verbo começar, a tendência para a subida do pronome é mais frequente com a preposição $a$ do que com $d e$.

Atente-se também nos exemplos (47) e (48) com trabalhar: sendo exemplos únicos e ambos da Crónica ${ }^{23}$, eles manifestam padrôes diferentes de colocação do

23. De facto, nestes textos encontra-se com mais frequência trabalhar-se de, que, como é expectável, 
pronome: assim, em (47) o argumento do verbo defender está junto do verbo finito contrariamente ao que acontece em (48) com o argumento de escusar.

Os exemplos com cuidar de são mais abundantes e há 13 casos como o de (49) com o pronome a ocorrer junto ao verbo finito. No entanto, foram também encontrados exemplos em que o clítico permanece junto ao verbo infinitivo, como em (50).

Muitos dos contextos em que o clítico se mantém junto ao verbo infinitivo são contextos de coordenaçáo, como os ilustrados em (16) e (17) e que aqui se repetem como (51) e (52):

(51) entendeu que se nô poderia teer com el rey dom Sãcho nem defender-sse delle. (CGE360,.5)

(52) E elles, quando esto vyrô, de cada parte me começaró de ameaçar e fazer-me muyto mal ẽ mynha terra quáto podyã. (CGE339,.12)

Olhando apenas para os contextos em que a subida do clítico não aconteceu, a maioria dos exemplos tem uma preposição a introduzir o verbo infinitivo (98 em 129 exemplos). Nestes casos, é importante averiguar qual a preposição ( $a$ ou de) e qual a posição do pronome (se é pré ou pós-verbal). $\mathrm{Na}$ Tabela 3 estão apresentados esses dados, tendo em conta o texto, de forma a possibilitar uma comparação com os dados que serão analisados na próxima secção.

\begin{tabular}{rrrrrrrrrr}
\hline & \multicolumn{2}{c}{ Arimateia } & \multicolumn{2}{c}{ Demanda } & \multicolumn{2}{c}{ Crónica } & \multicolumn{2}{c}{ TOTAL } \\
\hline posição & CL-Inf & Inf-CL & CL-Inf & Inf-CL & CL-Inf & Inf-CL & CL-Inf & Inf-CL & total \\
\hline a & 1 & 0 & 1 & 6 & 12 & 7 & 14 & 13 & 27 \\
de & 37 & 0 & 4 & 0 & 28 & 2 & 69 & 2 & 71 \\
\hline total & 38 & 0 & 5 & 6 & 40 & 9 & 83 & 15 & 98 \\
$\%$ & 100 & 0 & 45,5 & 54,5 & 81,6 & 18,4 & 84,7 & 15,3 & \\
\hline
\end{tabular}

Tabela 3. Posição do pronome clítico em contexto de não subida

nunca apresenta subida do pronome para o domínio superior, uma vez que este já alberga o pronome do verbo finito:

E por esto se trabalhou de os tirar da çidade per arte. (CGE759,.10)

Tanto amou e tanto se trabalhou de a enganar que o diabo lhe apareçeo hoje faz tres dias, (JAR99,.93)

Nos exemplos (47) e (48), o verbo trabalhar não ocorre com o pronome nem com a preposição, verificando-se subida e não subida do clítico respetivamente. 
No Arimateia, o único padrão possível é o clítico ocupar a posição pré-verbal seja com preposição $a$ (apenas uma ocorrência) seja com de (37 casos). Contrariamente, na Demanda, que tem menos casos, a preferência é pela posição pós-verbal do clítico quando o infinitivo é introduzido pela preposição a mas pela posição pré-verbal quando se trata da preposição de, sendo o único texto que exibe tendências opostas relativamente à posição do pronome com as preposiçôes $a$ e de. A Crónica segue a tendência do Arimateia sendo mais frequente a posição pré-verbal com ambas as preposiçôes, ainda que com a preposição $a$ a diferença não seja significativa.

Neste ponto, é pertinente mostrar alguns exemplos do pronome átono acusativo feminino $(a)$ nas oraçôes introduzidas pela preposição $a$, dada a proximidade fonética entre os dois elementos:

(53) E, ellas hyndo assy fazendo seu chanto, sairó a as receber seus irmãaos, el rei dom Affonsso e el rei dom Garcia, e o Cide Ruy Diaz e o côde de Cabra. (CGE469,.36)

(54) E, ante que chegassem à vylla, sayo a recebe-llas dom Airas Gonçalvez e a ellas prougue muyto com elle e preguntarô por el rei. (CGE469,.30)

Note-se que em (53) o clítico ocorre na posição pré-verbal, mostrando que foneticamente não há restriçóes para que o clítico possa estar junto à preposição. Em (54) apresenta-se um exemplo com os mesmos verbos e o mesmo clítico, ocorrendo este depois do verbo infinitivo.

$\mathrm{Na}$ secção seguinte, será descrita a colocação dos pronomes clíticos em contexto de oração de infinito preposicionado (simples e flexionado).

\subsection{Orações infinitivas introduzidas por preposição}

\subsubsection{Infinitivo simples}

O padrão de colocação dos pronomes clíticos em orações de infinitivo simples introduzidas por preposição é tratado nesta secção. Foram analisados 758 contextos de oraçôes infinitivas introduzidas pelas seguintes preposições: $a$, de, em, para, por, sem. A Tabela 4 mostra os resultados encontrados no corpus, tendo em conta o texto e a preposição. 


\begin{tabular}{rrrrrrrrrr}
\hline & \multicolumn{2}{c}{ Arimateia } & \multicolumn{2}{c}{ Demanda } & \multicolumn{2}{c}{ CróniCA } & \multicolumn{2}{c}{ TOTAL } \\
\hline posição & CL-Inf & Inf-CL & CL-Inf & Inf-CL & CL-Inf & Inf-CL & CL-Inf & Inf-CL & total \\
\hline a & 1 & 0 & 2 & 3 & 3 & 4 & 6 & 7 & 13 \\
$\%$ & 100 & 0 & 40 & 60 & 42,9 & 57,1 & 46,2 & 53,8 & \\
de & 61 & 2 & 95 & 2 & 169 & 1 & 325 & 5 & \\
$\%$ & 96,8 & 3,2 & 97,9 & 2,1 & 99,4 & 0,6 & 98,5 & 1,5 & 330 \\
em & 7 & 0 & 8 & 0 & 25 & 0 & 40 & 0 & \\
$\%$ & 100 & 0 & 100 & 0 & 100 & 0 & 100 & 0 & \\
para & 17 & 0 & 3 & 9 & 80 & 1 & 100 & 10 & \\
$\%$ & 100 & 0 & 25 & 75 & 98,8 & 1,2 & 90,9 & 9,1 & \\
por & 57 & 1 & 97 & 8 & 88 & 1 & 242 & 10 & \\
$\%$ & 98,3 & 1,7 & 92,4 & 7,6 & 98,9 & 1,1 & 96 & 4 & 252 \\
sem & 7 & 0 & 1 & 4 & 1 & 0 & 9 & 4 & \\
$\%$ & 100 & 0 & 20 & 80 & 100 & 0 & 69,2 & 30,8 & 13 \\
\hline total & 150 & 3 & 206 & 26 & 366 & 7 & 722 & 36 & \\
$\%$ & 98 & 2 & 88,8 & 11,2 & 98,1 & 1,9 & 95,3 & 4,7 & 758 \\
\hline
\end{tabular}

Tabela 4. Oraçôes de infinitivo simples introduzidas por preposição

Em termos gerais, pode verificar-se que há uma tendência quase generalizada para que o clítico esteja na posição pré-verbal nestas oraçôes infinitivas introduzidas por preposição (em mais de $95 \%$ dos contextos). De seguida, descreve-se o comportamento com cada uma das preposiçóes.

\subsubsection{Introduzidas por $a$}

Ao analisar as oraçóes não finitas introduzidas pela preposição $a$, Martins (1994: 119-123) observa que até meados do século XIV há sempre ênclise e, a partir daí, o padrão encontrado é sempre próclise. Nos três textos em análise há apenas 13 oraçôes não finitas com clíticos introduzidas por esta preposição: em seis casos o pronome está antes do infinitivo e nos restantes ocorre depois. Se no Arimateia há apenas um caso (e é de próclise (cf. (55)), na Demanda e na Crónica a ênclise é preferencial, ainda que com apenas mais um exemplo do que a próclise, mostrando variação no padrão de colocação do pronome. Alguns exemplos de ênclise podem estar relacionados com a pessoa/número do clítico que, no caso do pronome atóno acusativo feminino e singular, tem a mesma forma da preposição e, por isso, pode haver restriçôes fonéticas envolvidas (cf. (57) e (58)). Há, no entanto, outros exemplos em que um clítico da mesma natureza pode ocorrer antes (cf. (56)) ou depois do infinitivo (cf. (59)). 
(55) E, quando as gentes isto ouviram, foram mui ledos os que eram bautizados e os que nom eram correram mui presto a o receber. (JAR54,.40)

(56) e que lhe pedya que o costrangesse a lhe conhecer o senhorio e pagar o tributo como os outros reis. (CGE463,.6)

(57) ouuerom sabor de saber o que uos en queredes saber e meteron-se a busca-lla, asi como uos agora fazedes. (DSG97,.14)

(58) ẽ tal guisa que visse algũũa coussa das poridades do Santo Vasso, se he auentura que outorgada seja a acaba-la caualeiro peccador. (DSG370,.17)

(59) Mas que, quando se elle nô percuydar, que allo me achará conssigo a dar-lhe batalha. (CGE637,.21)

Os dados dos textos literários mostram que quer na Demanda quer na Crónica há oscilação na colocação do clítico, embora a ordem preferencial pareça ser verbo-clítico; já o exemplo único do Arimateia é insuficiente para fazer generalizações ainda que se possa avançar que a próclise é possível. Esta é também a tendência observada anteriormente sobre a colocação do clítico em contexto de não subida com infinitivos preposicionados (cf. Tabela 3).

\subsubsection{Introduzidas por de}

A preposição de é a mais frequente a introduzir oraçóes de infinitivo simples com clíticos, no total dos dados ${ }^{24}$. O clítico ocupa predominantemente a posição pré-verbal, sendo apenas cinco os casos de ênclise, quatro em contexto de coordenaçáo (cf. (60) e (61)). Há, no entanto, outros 10 casos de coordenação, em que o pronome ocupa a posição pré-verbal, ou seja, o padrão preferencial com esta preposição, como em (62) e (63).

(60) E seria bem de o leuarmos áá eẏgreẏa e bautiza-lo. (DSG278,.7)

(61) Sabede que esse é aquele que a todo seu poder muyto ha que se trabalha de enganar o homem e deita-lo da direita carreira e da direita fee e leva-lo a perdiçam de corpo e d' alma. (JAR86,.26)

(62) ja cavaleiro nom seria táo mortalmente ferido que, se houvesse lugar de ali chegar e se untar do sangue que do mumento saía suas chagas, que logo nom fosse são. (JAR119,.41)

(63) E os mayores da villa ouveró seu consselho de lhe dar a villa e $o$ receber por seu. (CGE559,.13)

24. Em termos de textos separadamente, apenas na Demanda não é a preposição que mais ocorre neste contexto, sendo ultrapassada unicamente por por. 
Os dados com esta preposição confirmam a generalização feita por Martins (1994: 109) quando afirma que há, em todas as épocas, uma preferência pela posição pré-verbal do clítico. E isto acontece mesmo em casos de coordenação. Esta tendência também já foi anteriormente confirmada relativamente aos dados de não subida com a preposição de a introduzir o infinitivo.

\subsubsection{Introduzidas por em}

Contrariamente ao que acontece nos textos notariais (com poucos dados com a preposição em e com alguma oscilação no padrão de colocação do pronome átono), nos textos literários agora em análise, o clítico ocorre obrigatoriamente antes do infinitivo, não existindo nenhum caso de ênclise, mesmo quando há coordenação.

(64) E, por a grande cortesya que recebera do Cide enno soltar e the dar o seu, e vẽedo outrossi os grandes feitos que fazia, teve por bem de casar seu filho, dó Sancho, cô dona Sol. (CGE670,.7)

A generalizaçáo feita por Martins (1994) sobre a preposição de não se estende à preposição em nos textos notariais, uma vez que a autora dá exemplos em que há oscilação na colocação do clítico. No entanto, no que aos textos literários diz respeito, pode observar-se que com a preposição $\mathrm{em}$ a posição do clítico é pré-verbal em todos os textos do corpus.

\subsubsection{Introduzidas por para}

A posição dos clíticos nas oraçôes não finitas introduzidas por para é maioritariamente antes do verbo, mesmo em casos de coordenaçáo, ainda que com esta preposição seja também possível encontrar exemplos em que o clítico ocorre depois do verbo infinitivo.

(65) E esto fazia ella porque cuidaua bem que vinha Gualaaz pos elles pera thes acorrer. (DSG231,.12)

(66) E, en todo esto, el rey avya mandado que lhe trouxessem da montanha hũu touro muy bravo e que lho deitassem pera o aver de matar. (CGE381,.21)

(67) Entom tirou delle a lança pera the dar outra ferida e o matar. (CGE379,.97)

(68) E ergeo-sse contra elle mas nom pera salua-llo mas pera fazer-lhe mal e pessar, se podesse. (DSG176,.13) 
Com a preposição para no século XIII e início do século XIV, a ordem era livre, de acordo com Martins (1994), no que se refere ao padrão de colocação de pronomes, estabilizando a partir da segunda metade do séc. xiv para a ordem clítico-verbo. O que os textos literários mostram é que no Arimateia a próclise é categórica e na Crónica é predominante (apenas com um exemplo de ênclise); na Demanda o padrão preferencial é a ênclise (cf. (68) acima), havendo alguns exemplos de próclise (cf. (65)).

\subsubsection{Introduzidas por por}

As oraçôes com infinitivo simples e clíticos introduzidas por por são das mais frequentes no corpus, sendo mesmo as mais encontradas na Demanda. Também com esta preposição, a posição preferencial para o pronome é antes do verbo (representando cerca de $96 \%$ das ocorrências), havendo pontualmente alguns casos de ênclise (cf. (69) e (74)).

(69) E por aqui entendereis que por guiar-vos dos perigos do mundo veyo Nosso Senhor Jesu Cristo vestido de sinal de vergindade e humildade, (JAR106,.66)

(70) - Por bóa fee, disse ele, por vos livrar e vos deitar daqui fora vim eu a este lugar. (JAR85,.34)

(71) E, quando a viu uîjr, marauilhou-sse e logo entendeo que era demo que the apareçera ẽ semelhança de donzella pollo ẽganar e $o$ meter ẽ pecado mortall. (DSG248,.18)

(72) E esto por reverẽça de seu padre e por the non seer desobediente nem the tornar mãaos iradas. (CGE780,.42)

(73) Em outro dia, de grãde manháa, foy o Cide ao paaço por veer el rei e se spedyr delle. (CGE662,.4)

(74) E o mouro penssou que o fazia em desdem; mas fezerô-lhe entender que era por honrra-lo. (CGE667,.16)

Olhando para cada texto isoladamente, observa-se que o texto que apresenta mais oscilação é a Demanda (oito casos de ênclise em 105 exemplos), tendo o Arimateia e a Crónica apenas um exemplo com o pronome em posição pós-verbal (cf. (69) e (74) respetivamente).

\subsubsection{Introduzidas por sem}

Quando a oração de infinitivo simples é introduzida pela preposição sem, a preferência também é de o clítico vir antes do verbo, no caso do Arimateia e da Crónica 
(a Crónica tem apenas uma ocorrência); nos exemplos da Demanda, o pronome vem quase sempre depois do verbo.

(75) E Nasciáo lhes perguntou por que o prenderam e o levavam assi sem o merecer e sem rezão. (JAR60,.18)

(76) E deixo-se jr a Lançalot sen nenhũa cousa lhe dezer. (DSG220,.11)

(77) E, pollo gram pesar que ende ouue, partio-se delles sem espedir-xe-lhes. (DSG348,.10)

Os exemplos com a ordem verbo-clítico não são expectáveis com esta preposição, já que, como assinala Martins (1994: 125), "dado o carácter de operador de negação predicativa desta preposição", a próclise deveria ser a única opção possível. Os dados da Demanda mostram que também com esta preposição podia haver alguma oscilação.

Em suma, a posição pré-verbal é a preferencial nas oraçôes de infinitivo simples introduzidas por preposição. Esta tendência mantém-se mesmo nos casos de coordenação: há 26 casos no corpus e apenas 4 apresentam o clítico em posição pós-verbal no segundo termo da coordenação (sempre com de). Dos 22 exemplos encontrados com próclise, 10 são com a preposição de, $2 \mathrm{com} e m, 1 \mathrm{com}$ para e $9 \mathrm{com}$ por. Não só a ênclise não é predominante nos casos de coordenação em termos gerais como também não é tendo em conta cada preposição individualmente. Assim, dos 36 casos de ênclise encontrados em oraçôes de infinitivo simples preposicionado apenas quatro exemplos são em contexto de segundo termo de uma comparaçáo (e sempre com de).

\subsubsection{Infinitivo flexionado}

Quanto à colocação dos pronomes clíticos em orações de infinitivo flexionado introduzidas por preposição, foram analisados 141 contextos de oraçóes infinitivas introduzidas pelas seguintes preposiçóes: $a$, de, em, para, por, sem. 


\begin{tabular}{rrrrrrrr}
\hline & \multicolumn{2}{c}{ Arimateia } & \multicolumn{2}{c}{ Demanda } & \multicolumn{2}{c}{ Crónica } \\
\hline & CL-Inf & Inf-CL & CL-Inf & Inf-CL & CL-Inf & Inf-CL & total \\
\hline $\mathrm{a}$ & 0 & 0 & 0 & 0 & 1 & 0 & 1 \\
$\%$ & 0 & 0 & 0 & 0 & 100 & 0 & 100 \\
$\mathrm{de}$ & 3 & 0 & 26 & 0 & 26 & 0 & 55 \\
$\%$ & 5,4 & 0 & 47,3 & 0 & 47,3 & 0 & 100 \\
$\mathrm{em}$ & 0 & 0 & 0 & 0 & 1 & 0 & 1 \\
$\%$ & 0 & 0 & 0 & 0 & 100 & 0 & 100 \\
para & 17 & 0 & & 1 & 15 & 0 & 33 \\
$\%$ & 51,5 & 0 & 0 & 3 & 45,5 & 0 & 100 \\
por & 12 & 0 & 28 & 0 & 10 & 0 & 50 \\
$\%$ & 24 & 0 & 56 & 0 & 20 & 0 & 100 \\
sem & 1 & 0 & 0 & 0 & 0 & 0 & 1 \\
$\%$ & 100 & 0 & 0 & 0 & 0 & 0 & 100 \\
\hline total & 33 & 0 & 54 & 1 & 52 & 0 & 141 \\
$\%$ & 23,4 & 0 & 38,3 & 0,7 & 37,6 & 0 & 100 \\
\hline
\end{tabular}

Tabela 5. Oraçôes de infinitivo flexionado introduzidas por preposição

A partir dos dados deste corpus, representados na tabela, uma generalização pode ser feita: em oraçóes de infinitivo flexionado preposicionadas, o clítico ocorre obrigatoriamente antes do verbo.

(78) E ella nos disse que se temya de a descobrirmos por que eramos muy moças. (CGE790,.24)

(79) Desi e Galaaz fez como el rey lhe disi por lho nô terẽ por orgulho (DSG389,.3)

(80) Mas nom esteve ali muito, quando lhe vieram prender o filho pera com seu pai o meterem na prisam. (JAR68,.19)

Há, no entanto, um caso com o clítico em posição pós-verbal:

(81) E quando a raỹa for iulgada à morte saca-la-an fora da uila pera queýmare-na. (DSG637,.12)

Sendo um caso único, poderia ser desprovido de importância. Note-se, no entanto, que o exemplo é com a preposição para e é da Demanda. Este texto apresenta apenas este exemplo de infinitivo flexionado introduzido por esta preposição. Como já tinha sido observado anteriormente, mesmo nos casos de infinitivo simples, neste texto, o padrão preferencial com a preposição para é verbo-clítico. 


\section{Consideraçóes finais}

Os dados descritos anteriormente não demonstram diferenças significativas relativamente às conclusóes que são conhecidas sobre a subida do clítico durante este período da língua (cf. Martins 1994; Fiéis e Madeira 2012). Assim, os dados deste corpus reforçam a generalização de que:

i) a subida do clítico é um fenómeno abundantemente atestado em PA e é muito mais frequente do que a não subida;

ii) há mais subida com a preposição $a$ a introduzir o verbo infinitivo do que com a preposição de.

O facto de terem sido usados textos com anotação sintática possibilitou a extração automática e a análise de uma maior quantidade de dados. Por não se pesquisar por determinado verbo ou por tipo de verbo, os resultados revelaram verbos com os quais a subida do clítico era possível em PA (como o verbo sair, sair a) ${ }^{25}$ mas que atualmente já não a permitem.

$\mathrm{Na}$ Tabela 6 estão representados os valores totais de subida e não subida, tendo em conta o texto.

\begin{tabular}{rrrrrrrrrr}
\hline & \multicolumn{1}{c}{ Arimateia } & \multicolumn{2}{c}{ DEmanda } & \multicolumn{2}{c}{ Crónica } & \multicolumn{2}{c}{ TOTAL } \\
\hline subida & sim & não & $\operatorname{sim}$ & não & $\operatorname{sim}$ & não & $\operatorname{sim}$ & não \\
\hline número & 640 & 49 & 1003 & 20 & 861 & 60 & 2504 & 129 & 2633 \\
$\%$ & 92,9 & 7,1 & 98 & 2 & 93 & 7 & 95 & 5 & 100 \\
\hline
\end{tabular}

Tabela 6. Valores de subida e não subida em cada texto

Em termos gerais, há $95 \%$ de subida do clítico. Dado o período em análise, estes valores náo são surpreendentes, mostrando que era um fenómeno generalizado em PA que foi perdendo expressividade ao longo da história do português ${ }^{26}$.

Se analisarmos cada texto individualmente, verifica-se que a Demanda (com 97,9\%) apresenta mais subida do que o Arimateia e a Crónica (ambos com cerca de

25. Andrade (2010: 219-220) também elenca este verbo entre os verbos do português clássico que permitem a subida do pronome.

26. A construção de reestruturação em português clássico é analisada por Andrade (2009). Os valores apresentados para a primeira metade do século Xvi sobre a subida do clítico são de quase $95 \%$ e para a segunda metade de $85 \%$. Também num estudo recente sobre a subida do clítico no falar de Braga e de Lisboa, Barbosa et al. (2017) mostram que os níveis de subida em português europeu contemporâneo continuam a ser bastante elevados (77\% de subida em Braga e 75\% em Lisboa) mas inferiores aos do PA. 
93\%). Estes valores são bastante expressivos na medida em que colocam a cópia quinhentista do Arimateia mais próxima da Crónica (um texto do século XIV) do que da cópia quatrocentista da Demanda que, apresentando valores mais altos na subida do clítico, se assemelha mais aos primeiros textos escritos em português. Uma vez que a cópia deste texto parece ser mais fiel ao original do que a cópia do Arimateia, na qual se assume explicitamente alguma modernização introduzida pelo(s) copista(s), a subida do clítico analisada neste trabalho vem sublinhar esse facto (cf. Martins 2013 para outras questóes linguísticas das duas cópias), já que, como é sabido, este fenómeno era generalizado em PA e foi, posteriormente, perdendo domínio.

No que diz respeito às oraçôes infinitivas não preposicionadas neste corpus do PA, este trabalho evidencia, em termos gerais, que:

i) há uma tendência clara para próclise em oraçôes de infinitivo simples preposicionado;

ii) existe obrigatoriedade de próclise em oraçóes de infinitivo flexionado preposicionado.

Olhando para a Tabela 7, verifica-se que o texto que exibe mais oscilação é a Demanda, apresentando mesmo, com algumas preposições, preferência pela ordem verbo-clítico, como a Tabela 4 acima revelou. O Arimateia e a Crónica apresentam valores semelhantes, tal como acontece com os dados relativos à subida do clítico.

\begin{tabular}{rrrrrrrrrr}
\hline & \multicolumn{2}{c}{ Arimateia } & \multicolumn{2}{c}{ Demanda } & \multicolumn{2}{c}{ Crónica } & \multicolumn{2}{c}{ TOTAL } \\
\hline posição & CL-V & V-CL & CL-V & V-CL & CL-V & V-CL & CL-V & V-CL & \\
\hline número & 150 & 3 & 206 & 26 & 366 & 7 & 722 & 36 & 758 \\
$\%$ & 98 & 2 & 88,8 & 11,2 & 98,1 & 1,9 & 95,3 & 4,7 & 100 \\
\hline
\end{tabular}

Tabela 7. Valores de próclise e ênclise em oraçóes de infinitivo simples preposicionadas em cada texto

Em relação às oraçôes de infinitivo simples preposicionadas é importante assinalar que:

1. os dados da Demanda revelam algum afastamento relativamente àquele que se tornará o padrão preferencial (próclise ao infinitivo) a partir de meados do século XIV (Martins 1994). Esse afastamento reflete-se concretamente em:

a) com a preposição a, a ênclise é predominante; 
b) variação com a preposição para, sendo a ênclise mais frequente;

c) mais oscilação com a preposição por na Demanda do que no Arimateia e na Crónica, que já evidenciam preferência pela colocação do pronome na posição pré-verbal;

d) com a preposição sem a ênclise, que é o padrão predominante, é surpreendente, já que, sendo uma preposição com valor negativo, esperar-se-ia que o clítico ocorresse em posição pré-verbal.

2. no Arimateia e na Crónica constata-se já alguma estabilidade no padrão de colocação dos pronomes clíticos nestes contextos, indiciando que se aproximam mais do português da segunda metade do século XIV.

Em suma, para além das questóes relacionadas com a colocação dos pronomes clíticos nos contextos analisados (i.e. complexos verbais de reestruturação e oraçôes de infinitivo preposicionado), este estudo também apresenta um contributo significativo, do ponto de vista filológico. Sendo o Arimateia e a Demanda cópias tardias de manuscritos do século XIII, os fenómenos inspecionados neste estudo apontam para graus diferentes de fidelização da cópia relativamente ao texto original: os dados da Demanda apresentam, de um modo geral, as propriedades descritas para os dados do período mais antigo da língua, como acontecia nos primeiros documentos notariais do século XIII, dando pistas para uma grande proximidade entre a cópia (quatrocentista) e o original (duocentista). Já a afinidade entre os dados da Crónica e do Arimateia aponta para um afastamento da cópia deste em relação ao original, colocando-o mais próximo do português dos séculos XIV-XV. Com este trabalho, fica claro que a intenção explícita do copista do Arimateia em modernizar algumas questôes também transparece em aspetos sintáticos como na colocação do pronome clítico em alguns contextos. 


\section{Referências bibliográficas}

Andrade, Aroldo Leal de. 2009. A subida de clíticos em português clássico: descrição e implicaçóes teóricas. Em Alexandra Fiéis e Maria Antónia Coutinho (eds.), Textos Seleccionados. XXIV Encontro Nacional da Associação Portuguesa de Linguistica. 81-95. Lisboa: APL.

Andrade, Aroldo Leal de. 2010. A subida de clíticos em português: um estudo sobre a variedade europeia dos séculos XVI a XX. Universidade Estadual de Campinas. (Dissertação de doutoramento).

Barbosa, Pilar, Maria da Conceição de Paiva e Kellen Cozine Martins. 2017. Clitic climbing in the speech of Braga and Lisbon. Em Pilar Barbosa, Maria da Conceiçẫo de Paiva e Celeste Rodrigues (eds.), Studies on Variation in Portuguese. 200-217. Amsterdam - Philadelphia: John Benjamins. https://doi.org/10.1075/ibll.14.08bar

Castro, Ivo. 1984. Livro de José de Arimateia (Estudo e Edição do COD. ANTT 643). Universidade de Lisboa. (Dissertação de doutoramento).

Cintra, Luís Filipe Lindley. 1951-1961. Crónica Geral de Espanha de 1344 [ed. crítica]. Lisboa: Academia Portuguesa da História.

Fiéis, Alexandra e Ana Madeira. 2012. Predicados de controlo na diacronia do português. Em Alexandra Fiéis e Maria Antónia Coutinho (eds.), Textos Selecionados, XXVII Encontro Nacional da Associação Portuguesa de Linguistica. 271-284. Lisboa: APL.

Gonçalves, Anabela, Ernestina Carrilho e Sandra Pereira. 2016. Predicados complexos numa perspetiva comparada. Em Ana Maria Martins e Ernestina Carrilho (eds.), Manual de Linguística Portuguesa. 523-557. Berlin - Boston: De Gruyter.

Gonçalves, Anabela, Inês Duarte e Matilde Miguel. 2007. On the status of prepositions in infinitival verb complements. Em Pablo Cano López, Isabel Fernández, Miguel González, Grabiela Prego e Montserrat Souto (eds), Actas del VI Congreso de Lingüistica General. Vol. II.A, Las lenguas y su estrucutura. 1599-1608. Madrid: Arco-Libros.

Gonçalves, Anabela. 1999. Predicados Complexos Verbais em Contextos de Infinitivo não Preposicionado do Português Europeu. Universidade de Lisboa. (Dissertaçáo de doutoramento).

Kayne, Richard. 1975. French Syntax: the transformational Cycle. Cambridge MA: MIT Press (Trad. francesa, Syntaxe du Français. Le Cycle transformationnel. Paris: Éditions du Seuil, 1977).

Magro, Catarina. 2005. Introdutores de oraçôes infinitivas - o que diz a sintaxe dos clíticos. Em Inês Duarte e Inês Leiria (eds.), Actas do XX Encontro Nacional da Associação Portuguesa de Linguística. 649-664. Lisboa: APL.

Magro, Catarina. 2007. Clíticos: variaçóes sobre o tema. Universidade de Lisboa. (Dissertação de doutoramento).

Martins, Ana Maria. 1994. Clíticos na História do Português. Universidade de Lisboa. (Dissertaçâo de doutoramento).

Martins, Ana Maria. 2013. Copiar o português duocentista: A Demanda e o José de Arimateia. Em Rosario Álvarez, Ana Maria Martins, Henrique Monteagudo e Maria Ana Ramos (eds.), Ao Sabor do Texto. Estudos dedicados a Ivo Castro. 383-402. Santiago de Compostela: Universidade de Santiago de Compostela.

Martins, Ana Maria. 2016a. Introduçấo: O português numa perspetiva diacrónica e comparativa. Em Ana Maria Martins e Ernestina Carrilho (eds.), Manual de Linguística Portuguesa. 1-39. Berlin / Boston: De Gruyter. https://doi.org/10.1515/9783110368840-003 
Martins, Ana Maria. 2016b. A colocação dos pronomes clíticos em sincronia e diacronia. Em Ana Maria Martins e Ernestina Carrilho (eds.), Manual de Linguistica Portuguesa. 401-430. Berlin Boston: De Gruyter. https://doi.org/10.1515/9783110368840-003

Mateus, Maria Helena Mira et al. 2003. Gramática da Lingua Portuguesa. Lisboa: Caminho.

Miranda, Sílvia. 2013. Reconstituição do ms. L da Crónica Geral de Espanha de 1344 (2a Parte). (Relatório Final de Estágio de Mestrado). http://repositorio.ul.pt/bitstream/10451/9403/1/ulf144050_ tm.pdf

Neto, Sílvio de A. Toledo. 2012-2015. Transcrição / Edição da Demanda do Santo Graal. (Manuscrito não publicado).

Pereira, Sandra. 2012. Protótipo de um glossário dos dialetos portugueses com informação sintática. Universidade de Lisboa. (Dissertação de doutoramento).

Rizzi, Luigi. 1982. Issues in Italian Syntax. Dordrecht: Foris.

Wanner, Dieter. 1987. The development of Romance Clitic Pronouns: from Latin to Old Romance. Berlin - New York: Mouton de Gruyter. 